\title{
Desempenho de vacas em lactação consumindo dietas contendo misturas de óleos essenciais
}

\section{Performance of lactating dairy cows fed diets containing mixtures of essential oils}

\author{
OLIVEIRA, Hudson Bernardes Nunes ${ }^{1 *}$; LEONEL, Fernando de Paula ${ }^{2}$; VILLELA, \\ Severino Delmar Junqueira ${ }^{1}$; LOBO JÚNIOR, Adalfredo Rocha ${ }^{3}$; GUIMARÃES, \\ Ewerton Couto $^{3}$; SANTIAGO, Bruno Tadeu ${ }^{1}$; CARVALHO, Jonas Marco de ${ }^{2}$; \\ RESENDE, Rafael José Vieira de ${ }^{2}$; ARAÚJO, Raphael Pavesi ${ }^{2}$
}

\footnotetext{
${ }^{1}$ Universidade Federal dos Vales do Jequitinhonha e Mucuri, Programa de Pós-Graduação em Zootecnia, Departamento de Zootecnia, Diamantina, Minas Gerais, Brasil.

${ }^{2}$ Universidade Federal de São João Del Rei, Faculdade de Zootecnia, Departamento de Zootecnia, São João Del Rei, Minas Gerais, Brasil.

${ }^{3}$ Universidade Federal dos Vales do Jequitinhonha e Mucuri, Faculdade de Ciências Agrárias, Departamento de Zootecnia, Diamantina, Minas Gerais, Brasil.

*Endereço para correspondência: hudsonbno@zootecnista.com.br
}

\section{RESUMO}

Objetivou-se com o presente trabalho avaliar os efeitos de uma mistura comercial de óleos essenciais (capsaicina, eugenol, cinamaldeído e carvacrol) microencapsulados com inclusões crescentes $(0 ; 1,5 ; 3,0$ e 4,0g/dia) sobre o consumo, digestibilidade, desempenho e a composição do leite de 20 vacas Holandesas primíparas confinadas em baias com cama de areia. Não houve interação entre os tratamentos e os períodos avaliados, e o efeito dos tratamentos não foi significativo $(\mathrm{P}>0,05)$ para as variáveis consumo de matéria seca, expresso em \% PV e em kg/dia, proteína bruta (\% PV), extrato etéreo (\% PV), fibra em detergente neutro (\% PV), fibra em detergente ácido (\% PV); digestibilidade da matéria seca (\%), proteína bruta $(\%)$, extrato etéreo (\%), fibra em detergente neutro $(\%)$; produção de leite $(\mathrm{kg})$ e seus componentes gordura (\%), proteína (\%), lactose $(\%)$, sólidos totais $(\%)$, extrato seco desengordurado (\%), contagem de células somáticas $(\log )$ e nitrogênio ureico $(\mathrm{mg} / \mathrm{dL})$. No entanto, avaliando separadamente os períodos testados, encontrou-se diminuição significativa $(\mathrm{P}<0,05)$ na produção de leite e aumento nas concentrações de sólidos totais (\%). Não houve diferença $(\mathrm{P}>0,05)$ para os teores de extrato seco desengordurado (\%) e contagem de células somáticas (log). Pôde-se concluir que a utilização de óleos essenciais contendo capsaicina, eugenol, cinamaldeído e carvacrol não influencia o consumo, digestibilidade, produção e composição do leite de vacas Holandesas primíparas.

Palavras-chave: capsaicina, carvacrol, cinamaldeído, eugenol

\section{SUMMARY}

The objective with the current study was to evaluate the effects of a commercial mixture of essential oils (capsaicin, eugenol, cinnamaldehyde, and carvacrol) microencapsulated with increasing inclusions $(0, \quad 1.5, \quad 3.0$ and $4.0 \mathrm{~g} /$ day $)$ on intake, digestibility, performance and milk composition of 20 primiparous Holstein cows confined in sand-bedded stalls. There was no interaction between treatment and observation periods, and the effect of treatments was not significant $(\mathrm{P}>0,05)$ for dry matter intake, expressed as $\%$ body weight (BW) and $\mathrm{kg} /$ day; crude protein (\% $\mathrm{BW})$; ether extract (\% BW); neutral detergent fiber; acid detergent fiber (\% BW); dry matter digestibility $(\%)$; crude protein $(\%)$; ether extract (\%); neutral detergent fiber (\%); milk production $(\mathrm{kg})$; milk fat $(\%)$; milk protein $(\%)$; lactose $(\%)$; total solids $(\%)$; nonfat dry extract $(\%)$; somatic cell count (log); and urea nitrogen $(\mathrm{mg} / \mathrm{dL})$. However, evaluating each period, a 
significant decrease $(\mathrm{P}<0,05)$ on milk production, and an increase in total solids concentrations $(\%)$ were observed. There was no difference $(\mathrm{P}>0,05)$ for total solids levels $(\%)$ and somatic cell count $(\log )$. We concluded that the use of essential oils containing capsaicin, eugenol, cinnamaldehyde and carvacrol does not affect intake, digestibility, and milk production and composition of primiparous Holstein cows.

Keywords: capsaicin, carvacrol, cinnamaldehyde, eugenol

\section{INTRODUÇÃO}

O uso de aditivos alimentares é uma ferramenta importante no que diz respeito à manipulação da fermentação ruminal, com objetivo de aumentar a produtividade e a eficiência na utilização dos recursos usados na alimentação animal. Nesse contexto, o uso de óleos essenciais pode se tornar uma alternativa viável de diminuição das perdas energéticas, melhoria das condições ruminais e redução da quantidade de poluentes como o metano $\left(\mathrm{CH}_{4}\right)$.

A utilização de compostos secundários de plantas (óleos essenciais) pode ser interessante devido a estes possuírem princípios ativos que podem ser utilizados isolados ou em conjunto com outros aditivos alimentares, conferindolhes diferentes modos de ação, dificultando um possível aparecimento de resistência bacteriana (ACAMOVIC \& BROOKER, 2005).

Embora, desde a antiguidade, os povos utilizem plantas na conservação de alimentos e como medicamentos, o estudo sistemático das mesmas como antibiótico é relativamente recente (OYARZABAL, 2011) e os seus efeitos dependem em grande parte da sua natureza química, concentração na dieta, quantidade consumida e do estado de saúde dos animais (ACAMOVIC \& BROOKER, 2005).

A utilização de óleos essenciais em estudos in vivo ainda é incipiente, de forma que se fazem necessárias avaliações destes compostos para determinar sua influência nas variáveis que influenciam o desempenho animal em todos os aspectos.

Portanto, objetivou-se com este estudo avaliar o consumo e a digestibilidade de nutrientes, o desempenho e composição do leite de vacas primíparas quando alimentadas com a inclusão de níveis crescentes de um composto de óleos essenciais microencapsulados.

\section{MATERIAL E MÉTODOS}

O experimento foi conduzido nas dependências da Fazenda Campo Alegre localizada no município de Ritápolis, MG (Latitude: $21^{\circ} 1$ ' 45,13 ''S e Longitude: $44^{\circ} 23^{\prime}$ 51' 'O). Foram utilizadas 20 vacas primíparas da raça Holandês, com massa corporal de $510 \pm 48 \mathrm{~kg}$, produção de leite de $28,5 \pm 3,6 \mathrm{~kg}$ e número de dias em lactação de $136 \pm 27$. Os animais foram distribuídos ao acaso em baias individuais $\left(2,2 \mathrm{~m}^{2}\right)$, cobertas, com piso de areia, dotadas de bebedouro e comedouros individuais e $\mathrm{o}$ delineamento experimental adotado foi o inteiramente casualizado em parcelas subdivididas no tempo em esquema 4 (tratamentos) $\times 3$ (períodos) $\times 5$ (repetições).

O experimento teve duração de 60 dias, divididos em três períodos de 20 dias, concentrando as coletas do $18^{\circ}$ ao $20^{\circ}$ dia de cada período e a dieta foi formulada para atender as exigências dos animais segundo as recomendações do National Research Council (NRC, 2001). A proporção em porcentagem na matéria seca dos ingredientes na dieta e os valores de macro e micro minerais para cada 
Rev. Bras. Saúde Prod. Anim., Salvador, v.15, n.3, p.670-678 jul./set., 2014 http://www.rbspa.ufba.br ISSN 15199940

$100 \mathrm{~g}$ da mistura estão apresentados na Tabela 1.

Os tratamentos utilizados foram: dieta basal sem inclusão de compostos de óleos essenciais (controle); adição de 1,5g/dia do composto; adição de 3,0g/dia do composto e adição de 4,5g/dia do composto, sendo o produto distribuído superficialmente sobre a ração no cocho.

Tabela 1. Proporção dos ingredientes na dieta e quantidade de macro e micro minerais para cada $100 \mathrm{~g}$ de mistura

\begin{tabular}{|c|c|c|c|c|c|c|c|c|c|c|}
\hline \multicolumn{11}{|c|}{ Alimento (\% MS) } \\
\hline $\begin{array}{c}\text { Silagem de } \\
\text { milho }\end{array}$ & & $\begin{array}{l}\text { Milho } \\
\text { moído }\end{array}$ & & & Polpa cítrica & & $\begin{array}{l}\text { o de } \\
\text { lão }\end{array}$ & Ureia & & $\begin{array}{l}\text { Núcleo } \\
\text { mineral }\end{array}$ \\
\hline 24,98 & & 26,53 & & & 17,34 & & & 0,6 & & 2,75 \\
\hline \multicolumn{5}{|c|}{ Macrominerais $(\mathrm{g} / \mathrm{kg})$} & \multicolumn{6}{|c|}{ Microminerais (ppm) } \\
\hline $\mathrm{Ca}$ & $\mathrm{P}$ & $\mathrm{Na}$ & $\mathrm{Mg}$ & $\mathrm{S}$ & $\mathrm{Co}$ & $\mathrm{Cu}$ & $\mathrm{Mn}$ & $\mathrm{Se}$ & $\mathrm{Zn}$ & $\mathrm{Fe}$ \\
\hline 210 & 90 & 60,5 & 10,5 & 10,5 & 150 & 1500 & 1250 & 30 & 3000 & 1500 \\
\hline
\end{tabular}

Legenda: $\mathrm{MS}=$ Matéria seca; $\mathrm{Ca}=$ Cálcio; $\mathrm{P}=$ Fósforo; $\mathrm{Na}=$ Sódio; $\mathrm{Mg}=$ Magnésio; $\mathrm{S}=$ Enxofre; $\mathrm{Co}=$ Cobalto $; \mathrm{Cu}=$ Cobre; $\mathrm{Mn}=$ Manganês; $\mathrm{Se}=$ Selênio $; \mathrm{Zn}=\mathrm{Zinco} ; \mathrm{Fe}=$ Ferro .

Foi oferecido suplemento mineral às vacas, sem ser quantificado quando estavam no piquete de descanso, período que ocorria entre 12:00 e 16:00 horas.

Foi testado um composto comercial de óleos essenciais, que possui como característica a microencapsulação, garantindo que todos os compostos sejam encontrados em uma única micropartícula e tenham liberação gradual e constante no meio ruminal. Os princípios ativos do produto foram a capsaicina, encontrada na pimenta; o eugenol, no cravo; o cinamaldeído, na canela e o carvacrol, no orégano.

A ração foi misturada diariamente em vagão misturador com balança automática acoplada, e o arraçoamento foi feito pouco antes de cada ordenha. Diariamente foram registradas as quantidades de alimentos fornecidos e das sobras de cada animal, para estimativa do consumo, permitindo-se sobras de $10 \%$. A média da composição bromatológica dos ingredientes e da dieta está apresentada na Tabela 2.
As amostras dos ingredientes foram coletadas uma vez em cada período, sendo feita uma amostra composta no final do experimento.

Amostras do alimento oferecido e das sobras foram coletadas nos três últimos dias de cada período experimento, para posterior caracterização.

As análises foram realizadas no Laboratório de Nutrição Animal da Universidade Federal dos Vales do Jequitinhonha e Mucuri, quanto aos teores de matéria seca (MS) segundo método INCT - CA G-003/1, proteína bruta (PB) segundo método INCT - CA $\mathrm{N}-001 / 1$, extrato etéreo (EE) segundo método INCT - CA G-004/1, matéria mineral (MM) segundo método INCTCA M-001/1, fibra em detergente neutro (FDN) segundo método INCT - CA F002/1, fibra em detergente ácido (FDA) segundo método INCT - CA F-004/1, fibra em detergente neutro indigestível (FDNi) segundo método INCT - CA F009/1 e fibra em detergente ácido indigestível (FDAi) segundo método INCT - CA F-011/1, conforme descrito por Detmann et al. (2012). 
Rev. Bras. Saúde Prod. Anim., Salvador, v.15, n.3, p.670-678 jul./set., 2014 http://www.rbspa.ufba.br ISSN 15199940

Tabela 2. Composição nutricional dos ingredientes e da dieta experimental

\begin{tabular}{lcccccc}
\hline Itens & $\begin{array}{c}\text { Silagem } \\
\text { de milho }\end{array}$ & $\begin{array}{c}\text { Milho } \\
\text { Moído }\end{array}$ & $\begin{array}{c}\text { Farelo de } \\
\text { soja }\end{array}$ & $\begin{array}{c}\text { Polpa } \\
\text { cítrica }\end{array}$ & $\begin{array}{c}\text { Caroço de } \\
\text { algodão }\end{array}$ & Dieta \\
\hline MS (\%) & 32,9 & 90,3 & 89,3 & 91,8 & 92,6 & 63,25 \\
PB (\%MS) & 8,9 & 8,4 & 49,6 & 9,8 & 25,1 & 20,5 \\
EE (\%MS) & 3,8 & 5,5 & 1,7 & 2,8 & 20,1 & 7,4 \\
MM (\%MS) & 3,3 & 1,3 & 6,6 & 8,3 & 5,1 & 5,7 \\
FDN (\%MS) & 42,3 & 10,6 & 11,9 & 25,5 & 41,2 & 27,1 \\
FDA (\%MS) & 21,3 & 2,6 & 6,5 & 17,0 & 30,5 & 12,4 \\
FDNi (\%FDN) & 15,0 & 5,0 & 5,8 & 9,1 & 18,1 & 9,8 \\
FDAi (\%FDA) & 7,0 & 2,8 & 2,7 & 5,4 & 14,0 & 5,3 \\
\hline
\end{tabular}

MS = matéria seca; $\mathrm{PB}=$ proteína bruta; $\mathrm{EE}=$ extrato estéreo; $\mathrm{MM}=$ matéria mineral; $\mathrm{FDN}=$ fibra em detergente neutro; FDA = fibra em detergente ácido; FDNi = fibra em detergente neutro indigestível; FDAi = fibra em detergente ácido indigestível.

As mesmas análises também foram repetidas para as fezes, exceto FDA. Foi realizada também a coleta de fezes para a determinação indireta da produção fecal (kg MS/dia) por meio de indicadores internos, estimada baseando-se na razão entre a quantidade de FDAi consumido e sua concentração nas fezes (MORAIS et al., 2010).

Produção fecal $(\mathrm{kg}$ MS/dia $)=F D A i$ ingerido ( $\mathrm{g} /$ dia) / FDAi nas fezes ( $\mathrm{g} / \mathrm{kg} M S$ )

Com os resultados da produção fecal foram calculadas as digestibilidades aparente da MS, PB, EE e FDN conforme a seguinte fórmula.

Digestibilidade $=($ Dieta ingerida (g/dia) / Produção fecal ( $\mathrm{g} /$ dia $)) \times 100$

As ordenhas foram realizadas três vezes ao dia às 2:00, 10:00 e 18:00 horas, com ordenhadeira mecânica. No $1^{\circ}$ dia de coleta de cada período foi feita a pesagem do leite por meio de leitores digitais e corrigido para gordura a $4 \%$, segundo National Research Council (NRC, 2001), a amostragem foi realizada acoplando-se um medidor na ordenhadeira. Após o término da ordenha, tomou-se o cuidado de deixar entrar ar no medidor por no mínimo 15 segundos para homogeneização da amostra, transferindo em seguida para o frasco onde continha o conservante

\author{
Bronopol $^{\circledR} \quad$ (2-bromo-2-nitro-1,3- \\ propanodiol).
}

As amostras de leite foram identificadas e enviadas para Clínica do Leite, ESALQ-USP, onde foram feitas as análises de gordura, proteína, lactose, sólidos totais, extrato seco desengordurado, nitrogênio ureico e contagem de células somáticas.

Realizou-se a análise de variância (ANOVA) para todas as variáveis em estudo usando-se um modelo linear que contemplava os efeitos fixos de inclusão de níveis crescentes de óleo na dieta, período recebendo a dieta e suas interações. Os dados foram analisados como medidas repetidas no tempo. As correlações existentes entre as medidas tomadas no mesmo animal e a produção antes do início do experimento foi usada como covariável para verificar se a produção prévia influenciou o resultado. Desta forma, a ANOVA foi realizada usando o procedimento MIXED do SAS versão 9.2 (SAS INSTITUTE, 2008), onde animal foi incluído na opção SUBJECT da afirmação REPEATED. A melhor estrutura de covariância para a ANOVA foi escolhida com base no menor valor obtido pelo Bayesian Information Criterion (BIC) em cada variável. Quando efeitos significativos $(\mathrm{P}<0,05)$ foram detectados para 
qualquer um dos efeitos estudados na ANOVA, aplicou-se um teste $t$-Student para discriminar as médias de quadrados mínimos. Quando efeitos significativos não foram detectados $(\mathrm{P}>0,05)$, realizou-se uma análise descritiva, usando o procedimento MEANS do SAS.

\section{RESULTADOS E DISCUSSÃO}

Existem variações no desempenho animal com a utilização dos óleos essenciais, principalmente devido a diferenças na sua composição, quantidades administradas e influência de fatores externos, tais como, diferentes dietas e estágio de lactação.

No presente estudo não houve interação $(\mathrm{P}>0,05)$ entre os tratamentos $\mathrm{e}$ os períodos em que foram avaliados e nem diferença significativa $(\mathrm{P}>0,05)$ dos tratamentos sobre as variáveis de consumo e digestibilidade de nutrientes (Tabela 3).

A ausência de efeito sobre as variáveis consumo e digestibilidade de nutrientes pode estar associada ao fato do composto de óleos essenciais não terem influenciado o CMS dos animais, seja pela ausência de melhora na palatabilidade e/ou pela falta de efeito sobre os microrganismos ruminais. Assim, não houve diferença também na digestibilidade dos nutrientes.

Considerando-se em trabalhos in vitro (BENCHAAR et al., 2008; CALSAMIGLIA et al., 2007; GLADINE et al., 2007), pode-se inferir a falta de efeito sobre os microrganismos ruminais à adaptação dos mesmos ao produto durante o período de adaptação à dieta. Fato esse, reforçado pela afirmação de Spanghero et al. (2009), quando relataram que a matriz que reveste os óleos essenciais, também presente no produto usado neste trabalho, promove contato gradual dos microrganismos com o produto, facilitando essa adaptação.

$\mathrm{O}$ efeito da palatabilidade não foi mensurado, pois o óleo essencial foi misturado somente superficialmente sobre a ração com intuito de fazer com que os animais consumissem totalmente o mesmo. Assim, as vacas podem ter percebido as características que dão melhor palatabilidade à dieta apenas nos primeiros bocados, diminuindo esse efeito posteriormente.

Fica claro em outros estudos como os de Fandiño et al. (2008) e Cardozo et al. (2006) que a ação de alguns óleos essenciais estimula o consumo. Esses autores constataram que o óleo essencial de pimenta aumentou o CMS de bovinos. Portanto, o tema ainda não foi esgotado, e fazem-se necessários mais estudos.

É importante destacar que vacas primíparas possuem menor consumo quando comparadas às multíparas e maior valor de consumo relativo (\% do peso do corporal), pois possuem menor peso corporal (NRC, 2001). Assim, as médias de CMS (\% PV) estão dentro das estimativas do National Research Council (2001) para essa categoria de animais.

Quanto à digestibilidade, essa está ligada com a taxa de passagem, dependente principalmente da quantidade e qualidade do alimento e da adaptação dos microrganismos que irão utilizar tal substrato. Assim, como não houve diferença nas variáveis CMS em \% PV e $\mathrm{kg} / \mathrm{dia}$, provavelmente, também não houve diferença na ação dos microrganismos sobre o alimento ou essa não foi evidenciada, pois, a digestibilidade não diferiu estatisticamente (Tabela 3).

No presente estudo, a produção e componentes do leite não diferiram 
$(\mathrm{P}>0,05)$ entre os tratamentos (Tabela 4), pois, o aporte de nutrientes advindos da alimentação não foi maior a ponto de aumentar sua produção e nem o metabolismo do animal e da sua microbiota influenciaram essas características. Portanto, essa similaridade da produção pode ser justificada também pela falta de efeito das variáveis de consumo e de digestibilidade da dieta (Tabela 3).

Tabela 3. Efeito de níveis de óleo essencial na dieta de vacas leiteiras sobre o consumo e digestibilidade de nutrientes

\begin{tabular}{|c|c|c|c|c|c|c|c|c|c|}
\hline \multirow{3}{*}{ Variável } & \multicolumn{8}{|c|}{ Tratamentos } & \multirow{3}{*}{$\begin{array}{l}\text { Valor } \\
\text { de P }\end{array}$} \\
\hline & \multicolumn{2}{|c|}{ CTL } & \multicolumn{2}{|c|}{ OE 1,5} & \multicolumn{2}{|c|}{ OE 3,0} & \multicolumn{2}{|c|}{$\mathrm{OE} 4,5$} & \\
\hline & Média & $\mathrm{CV}(\%)$ & Média & $\mathrm{CV}(\%)$ & Média & $\mathrm{CV}(\%)$ & Média & $\mathrm{CV}(\%)$ & \\
\hline CMS (\% PV) & 3,81 & 13,97 & 3,48 & 8,54 & 3,51 & 8,89 & 3,6 & 14,0 & 0,45 \\
\hline CMS (kg/dia) & 19,42 & 13,97 & 17,77 & 8,54 & 17,90 & 8,89 & 18,36 & 14,0 & 0,45 \\
\hline CPB (\% PV) & 0,79 & 22,19 & 0,74 & 18,23 & 0,74 & 17,05 & 0,76 & 20,4 & 0,45 \\
\hline CEE (\% PV) & 0,29 & 26,83 & 0,28 & 24,20 & 0,28 & 24,31 & 0,28 & 25,4 & 0,52 \\
\hline CFDN (\% PV) & 1,04 & 13,56 & 0,95 & 8,30 & 0,95 & 9,09 & 0,97 & 14,9 & 0,43 \\
\hline CFDA (\% PV) & 0,47 & 14,54 & 0,43 & 9,92 & 0,43 & 9,40 & 0,44 & 17,1 & 0,51 \\
\hline DIG_MS (\%) & 63,0 & 14,90 & 65,0 & 14,22 & 65,0 & 10,92 & 66,0 & 13,1 & 0,63 \\
\hline DIG_PB (\%) & 66,0 & 17,44 & 69,0 & 20,06 & 71,0 & 16,84 & 70,0 & 18,0 & 0,39 \\
\hline DIG_EE (\%) & 79,0 & 9,19 & 80,0 & 11,64 & 79,0 & 12,85 & 83,0 & 9,48 & 0,42 \\
\hline DIG_FDN $(\%)$ & 42,0 & 40,36 & 45,0 & 29,61 & 42,0 & 31,54 & 42,0 & 34,7 & 0,96 \\
\hline
\end{tabular}

$\mathrm{CTL}=$ sem a inclusão de óleos essenciais; $\mathrm{OE} 1,5=1,5 \mathrm{~g} /$ dia do composto; $\mathrm{OE} 3=3 \mathrm{~g} /$ dia do composto; $\mathrm{OE} 4,5$ = 4,5 g/dia do composto; \% PV = Porcentagem do peso vivo; CMS = Consumo de matéria seca; $\mathrm{CPB}=$ Consumo de Proteína bruta; $\mathrm{CEE}=$ Consumo de extrato etéreo; $\mathrm{CFDN}=$ Consumo de fibra em detergente neutro; CFDA = Consumo de fibra em detergente ácido; DIG_MS = Digestibilidade da matéria seca; DIG_PB = Digestibilidade da proteína bruta; DIG_EE = Digestibilidade do extrato etéreo; DIG_FDN $=$ Digestibilidade da fibra em detergente neutro.

Tabela 4. Efeito de níveis de óleo essencial na dieta de vacas leiteiras sobre a produção de leite e seus componentes

\begin{tabular}{|c|c|c|c|c|c|c|c|c|c|}
\hline \multirow{3}{*}{ Variável } & \multicolumn{8}{|c|}{ Tratamentos } & \multirow{3}{*}{$\begin{array}{l}- \text { Valor } \\
-\quad \text { de P }\end{array}$} \\
\hline & \multicolumn{2}{|c|}{ CTL } & \multicolumn{2}{|c|}{ OE 1,5} & \multicolumn{2}{|c|}{ OE 3,0} & \multicolumn{2}{|c|}{$\mathrm{OE} 4,5$} & \\
\hline & Média & $\mathrm{CV}(\%)$ & Média & $\mathrm{CV}(\%)$ & Média & $\mathrm{CV}(\%)$ & Média & $\mathrm{CV}(\%)$ & \\
\hline PL (kg) & 30,11 & 11,59 & 27,53 & 9,79 & 26,66 & 13,03 & 27,18 & 14,41 & 0,26 \\
\hline PLCG (kg) & 23,64 & 20,07 & 22,10 & 22,76 & 21,99 & 20,00 & 22,53 & 27,28 & 0,93 \\
\hline GORD $(\%)$ & 2,20 & 31,63 & 2,32 & 43,26 & 2,47 & 44,61 & 2,47 & 49,19 & 0,95 \\
\hline PROT $(\%)$ & 3,04 & 6,15 & 3,10 & 13,24 & 3,25 & 4,48 & 3,06 & 14,32 & 0,76 \\
\hline $\mathrm{LAC}(\%)$ & 4,63 & 6,26 & 4,61 & 5,84 & 4,75 & 3,30 & 4,57 & 3,89 & 0,32 \\
\hline ST $(\%)$ & 10,88 & 5,99 & 12,10 & 23,14 & 11,45 & 10,62 & 11,10 & 12,25 & 0,30 \\
\hline $\operatorname{ESD}(\%)$ & 8,67 & 4,94 & 8,65 & 6,96 & 8,99 & 2,83 & 8,63 & 5,33 & 0,46 \\
\hline CCS (log) & 4,59 & 27,02 & 4,93 & 26,00 & 4,5 & 12,84 & 4,74 & 32,18 & 0,40 \\
\hline $\mathrm{NU}(\mathrm{mg} / \mathrm{dL})$ & 14,02 & 18,20 & 14,82 & 16,23 & 15,82 & 23,54 & 16,11 & 21,04 & 0,70 \\
\hline
\end{tabular}

Legenda: $\mathrm{CTL}=$ controle; $\mathrm{OE} 1,5=1,5 \mathrm{~g} /$ dia do composto; OE3 $=3 \mathrm{~g} /$ dia do composto; OE4,5 $=4,5$ $\mathrm{g} /$ dia do composto; $\mathrm{PL}=$ Produção de leite; $\mathrm{PLCG}=$ Produção de leite corrigida para gordura $4 \%$; GORD = Gordura do leite; PROT = Proteína do leite; LAC = Lactose; $\mathrm{ST}=$ Sólidos totais; ESD = Estrato seco desengordurado; $\mathrm{CCS}=$ Contagem de células somáticas; $\mathrm{NU}=$ Nitrogênio ureico do leite.

Vale ressaltar que, mesmo não havendo diferença significativa de GORD, os valores observados foram baixos, o que pode ter sido causado pelo alto teor de concentrado presente na ração, levando à menor relação de acetato/propionato. 
Possivelmente o ambiente ruminal também estava com $\mathrm{pH}$ mais baixo que o normal e os animais estavam em condições de provável distúrbio metabólico, o que pode ser evidenciado pela inversão da relação gordura/proteína no leite.

Quando se avaliou os efeitos dos períodos sobre a produção e composição do leite, constatou-se diferença significativa $(\mathrm{P}<0,05)$ para as variáveis de PL, GORD, PROT, LAC, ST e NU (Tabela 5). Entretanto, não houve interação dos tratamentos com os períodos e a redução na produção de leite era esperada, fato que pode ser explicado pela curva de lactação de vacas leiteiras, pois os animais já haviam passado do pico de lactação, havendo maior concentração dos sólidos no leite aumentando seus valores, exceto a GORD, que teve aumento expressivo no último período, pelo fato da menor seleção de concentrado e melhor utilização da fibra da dieta.

O ESD não foi diferente $(\mathrm{P}>0,05)$ entre os períodos, mostrando que a GORD foi responsável pelo aumento no ST e o menor valor do NU no segundo período é indicativo de que houve melhor eficiência na utilização da proteína da dieta nesse período. Já a CCS, CMS e CFDN não diferiram $(\mathrm{P}>0,05)$ entre os períodos e as médias de consumo apresentadas estão de acordo com os valores estimados pelo National Research Council (NRC, 2001) para essa categoria animal (Tabela 5).

Tabela 5. Efeito de período sobre o desempenho, componentes do leite e consumo de vacas leiteiras primíparas

\begin{tabular}{|c|c|c|c|c|}
\hline \multirow{2}{*}{ Variável } & \multicolumn{3}{|c|}{ Período } & \multirow{2}{*}{ Valor de $\mathrm{P}$} \\
\hline & $1^{\circ}$ & $2^{\circ}$ & $3^{\circ}$ & \\
\hline PL (kg) & $28,5^{\mathrm{a}}(0,80)$ & $28,0^{\mathrm{ab}}(0,80)$ & $27,0^{\mathrm{b}}(0,82)$ & 0,03 \\
\hline PLCG (kg) & $21,4(0,81)$ & $21,71(1,00)$ & $25,45(1,89)$ & 0,25 \\
\hline GORD (\%) & $2,0^{\mathrm{b}}(0,22)$ & $2,1^{\mathrm{b}}(0,21)$ & $3,2^{\mathrm{a}}(0,27)$ & $<0,01$ \\
\hline PROT (\%) & $3,0^{\mathrm{b}}(0,08)$ & $3,1^{\mathrm{ab}}(0,08)$ & $3,2^{\mathrm{a}}(0,08)$ & 0,04 \\
\hline LAC $(\%)$ & $4,7^{\mathrm{a}}(0,05)$ & $4,6^{\mathrm{b}}(0,05)$ & $4,6^{\mathrm{b}}(0,06)$ & 0,03 \\
\hline ST $(\%)$ & $10,8^{\mathrm{b}}(0,29)$ & $10,8^{\mathrm{b}}(0,15)$ & $13,0^{\mathrm{a}}(0,57)$ & $<0,01$ \\
\hline ESD (\%) & $8,8(0,11)$ & $8,7(0,11)$ & $8,8(0,12)$ & 0,53 \\
\hline CCS (log) & $4,35(34,80)$ & $4,8(38,03)$ & $4,9(40,08)$ & 0,36 \\
\hline $\mathrm{NU}(\mathrm{mg} / \mathrm{dL})$ & $16,2^{\mathrm{a}}(0,64)$ & $13,5^{\mathrm{b}}(0,62)$ & $16,3^{\mathrm{a}}(0,71)$ & $<0,01$ \\
\hline CMS (\% PV) & $3,57(0,46)$ & $3,51(0,31)$ & $3,75(0,69)$ & 0,12 \\
\hline CMS (kg/dia) & $18,24(0,46)$ & $17,88(0,31)$ & $19,01(0,69)$ & 0,12 \\
\hline CFDN (\% PV) & $0,96(0,13)$ & $0,98(0,09)$ & $1,00(0,19)$ & 0,37 \\
\hline
\end{tabular}

Médias de quadrados mínimos (erro padrão); \% PV = Porcentagem do peso vivo; PL = Produção de leite; PLCG = Produção de leite corrigida para gordura $4 \%$; GORD = Gordura do leite; PROT = Proteína do leite; $\mathrm{LAC}=$ Lactose $; \mathrm{ST}=$ Sólidos totais; ESD = Estrato seco desengordurado; $\mathrm{CCS}=$ Contagem de células somáticas; NU = Nitrogênio ureico; CMS = Consumo de matéria seca; CFDN = Consumo de fibra em detergente neutro; ${ }^{\mathrm{a}, \mathrm{b}, \mathrm{c}}$ Médias seguidas por diferentes letras entre os períodos diferem estatisticamente $(\mathrm{P}<0,05)$ pelo teste de $t$-Student.

Para melhor elucidar os fenômenos advindos da utilização desses óleos são necessários mais estudos com abordagem da dosagem ótima, forma adequada de fornecimento e relação custo benefício.

Os níveis do composto de óleos essenciais não influenciaram $o$ 
Rev. Bras. Saúde Prod. Anim., Salvador, v.15, n.3, p.670-678 jul./set., 2014 http://www.rbspa.ufba.br ISSN 15199940

consumo, a digestibilidade, nem a produção e composição do leite de vacas primíparas da raça Holandês.

\section{REFERÊNCIAS}

ACAMOVIC, T.; BROOKER, J.D. Biochemistry of plant secondary metabolites and their effects in animals. The Proceedings of the Nutrition Society, v.64, n.3, p.403-412, 2005.

BENCHAAR, C.; McALLISTER, T.A.; CHOUINARD, P.Y. Digestion, ruminal fermentation, ciliate protozoal populations, and milk production from dairy cows fed cynnamaldehyde, quebracho condensed tannin, or Yucca schidigera saponin extracts. Journal of Dairy Science, v.91, n.12, p.4765-4777, 2008.

CALSAMIGLIA, S.; BUSQUET, M.; CARDOZO, P.W.; CASTILLEJOS, L.; FERRET, A. Invited review: Essential oils as modifiers of rumen microbial fermentation. Journal of Dairy

Science, v.90, p.2580-2595, 2007.

CARDOZO, P.W.; CALSAMIGLIA, S.; FERRET, A.; KAMEL, C. Effects of alfalfa extract, anise, capsicum, and a mixture of cynnamaldehyde and eugenol on ruminal fermentation and protein degradation in beef heifers fed a high concentrate diet. Journal of Animal Science, v.84, n.10, p.28012808, 2006.

DETMANN, E.; SOUZA, M.A.; VALADARES FILHO, S.C. Métodos para Análise de Alimentos. Instituto Nacional de Ciência e Tecnologia de Ciência Animal. Visconde do Rio Branco: Suprema, 2012. 214p.
FANDIÑO, I.; CALSAMIGLIA, S.; FERRET, A.; BLANCH, M. Anise and capsicum as alternatives to monensin to modify rumen fermentation in beef heifers fed a high concentrate diet. Animal Feed Science and Technology, v.145, n.1/4, p.409-417, 2008.

GLADINE, C.; ROCK, E.; MORAND, C.; BAUCHART, D.; DURAND, D. Bioavailability and antioxidant capacity of plant extracts rich in polyphenols, given as a single acute dose, in sheep made highly susceptible to lipoperoxidation. British Journal of Nutrition, v.98, p.691-701, 2007.

MORAIS, J.A.S.; BERCHIELLI, T.T.; OLIVEIRA, S.G.; QUEIROZ, M.F.S.; TORO-VELÁSQUEZ, P.A.; RIVERA, A. Diferentes procedimentos na determinação de indicadores internos para estimativa de produção fecal e fluxo duodenal de matéria seca em bovinos. Acta Scientiarum. Animal Sciences, v.32, n.2, p.213-218, 2010.

NATIONAL RESEARCH COUNCIL NRC. Nutrient Requirements of Dairy Cattle. Washington, D.C.: National Academies Press, 2001.

OYARZABAL, M.E.B. Aplicação do óleo essencial do orégano (Origanumvulgare) no tratamento da mastite bovina e presença de fungos no leite bovino in natura. 2011. 74f. Tese (Doutorado em Ciências Veterinárias) - Faculdade de Veterinária, Universidade Federal do Rio Grande do Sul, Porto Alegre. 
Rev. Bras. Saúde Prod. Anim., Salvador, v.15, n.3, p.670-678 jul./set., 2014 http://www.rbspa.ufba.br ISSN 15199940

SPANGHERO, M.; ROBINSON, P.H.;

ZANFI, C.; FABBRO, E. Effect of

increasing doses of a microencapsulated

blend of essential oils on performance

of lactating primiparous cows. Animal

Feed Science and Technology, v.153,

n.1/2, p.153-157, 2009.

Data de recebimento: 02/02/2014

Data de aprovação: 23/09/2014 